\title{
Application of the multi-criteria decision method ELECTRE III for the Weapon selection
}

\author{
Hamid Esna Ashari ${ }^{\mathbf{a}}$ and Masoud Parsaei ${ }^{\mathbf{b}^{*}}$
}

${ }^{a}$ Department of Industrial Engineering, Islamic Azad University, Arak Branch, Arak, Iran

${ }^{b}$ Department of Industrial Engineering, Islamic Azad University, Zahedan Branch, , Zahedan, Iran

\section{H R O N I C L E}

Article history:

Received February 14, 2014

Accepted May 29, 2014

Available online

June 82014

Keywords:

Weapon selection

Multiple criteria decision-making

ELECTRE III

Simos method \begin{abstract}
A B S T R A C T
Selection of suitable weapon for armed forces is one of the most complex decisions, which must be taken by martial administrators. The procedure of decision making on weapon selection is integrated with various criteria, which are often in conflict. This paper presents a multi criteria decision making problem based on the implementation of ELECTRE III technique. The proposed model compares all acceptable choices based on a systematic and sophisticated procedure and provides some efficient solutions. The implementation of the proposed model is demonstrated for an infantry rifle selection. The proposed model, first, determines acceptable choices and criteria through Simos method and then it uses ELECTRE III to rank various alternatives. The result of the application of the proposed model for a real-world case study of choosing an infantry rifle indicates its effectiveness.
\end{abstract}

(C) 2014 Growing Science Ltd. All rights reserved.

\section{Introduction}

Swift improvements in martial sciences and technologies have led to production of more effective equipment and instruments than the existing ones, which would create obsolescence of the available equipment throughout time. Therefore, updating martial equipment and instruments is one of the main activities, which should be performed constantly by martial forces. Suitable and update equipment plays essential role in armed forces' defy power improvement. Infantry rifle is one of the main equipment used by armed forces in almost all martial operations. Infantry rifle could be introduced as a martial instrument with advantages over the other existing equipment in any other army from the viewpoint of number and from the perspective of its utility by armed forces. Many countries use a fixed type of infantry rifle with an old technology over the years. However, new and advanced forms of this weapon type have been introduced to market, which maintain higher efficiency than the older ones. During the past few years, some of these countries try to modify infantry rifle available in their armed forces and choose a new infantry rifle. Choosing a new weapon from existing choices on the market is a main challenge that martial administrators are faced with in this stage. This is because making a mistake weapon selection could hurt armed forces efficiency and

* Corresponding author

E-mail address: masoudparsaei62@gmail.com (M. Parsaei)

(C) 2014 Growing Science Ltd. All rights reserved.

doi: $10.5267 /$ j.dsl.2014.6.001 
it could lead to financial damages. In order for preventing negative effects derived from mistake in weapon selection, a precise and widespread assessment must be performed about this choice through extensive information collection about the existing choices. Although weapon selection plays an essential role on the design of an effective defense system, the publications on this subject are limited (Dagdeviren et al., 2009). Mon et al. (1994) applied analytical hierarchy process (AHP) method in phase condition and based on entropy weight for evaluation and selection of weapon systems. Cheng (1996) applied Fuzzy AHP (FAHP) for naval tactical missile systems assessment. Cheng and Mon (1994) used AHP method based on fuzzy scales in a supposed anti-aircraft artillery system selection case. Chen (1996) performed weapon systems assessment based on fuzzy arithmetic operations. Cheng et al. (1999) utilized analytical hierarchy process (AHP) by implementation of linguistic variable weight to evaluate attack helicopters. Cheng (1999) used ranking fuzzy numbers for assessing weapon systems after correcting the existing errors in Chen (1996). Cheng and Lin (2002) applied fuzzy decision theory with linguistic criteria to select the best main battle tank. Dagdeviren et al. (2009) proposed a model for weapon selection by merging AHP and Fuzzy TOPSIS. Lee et al. (2010) proposed a new model for weapon systems selection that combined analytic hierarchy process (AHP), principal component analysis (PCA) and goal programming (GP).

Choosing a new weapon is a strategic decision making for armed forces, which has a high complexity. Decision making complexity in weapon selection procedure is because of the criteria, which must be considered, simultaneously. In addition, most of these criteria are contradictory and increase in one of the criteria's compliance might reduce the other's compliance. This is because there are literally many choices for administrators and each choice is preferred over the other in a criterion or several criteria. Therefore, in order to select the best weapon from different existing choices on the market we need to consider various criteria. The multiple criteria decision making (MCDM) methods enjoy the capability of offering assistance to management within a coherent and logical framework to allow them to choose the best alternative by considering various criteria and by evaluating all the alternatives. This methods help us improve quality of decisions by making them more explicit, rational and efficient (Pohekar \& Ramachandran, 2004; Wang \& Triantaphyllou, 2008). Over the years, several MCDM methods have been proposed in various areas, with different theoretical background and facing challenging questions and providing different kinds of results (Pavan \& Todeschini, 2009). Hwang and Yoon (1981) have presented a survey of the MCDM methods. One of the various multi-criteria methods is the outranking approach, which proceeds by a pairwise comparison of alternatives for each single criterion in order to determine partial binary relationship denoting the strength of preference of alternative $a$ over alternative $b$ (Cavallaro, 2010). The outranking relation of $a S b$ indicates that $a$ outranks $b$, if a is at least as good as $b$ on a majority of criteria and this result is not substantially based on any of the other criteria (Kaya \& Kahraman, 2011; Papadopoulos \& Karagiannidis, 2008; Roy, 1968). Outranking methods has been frequently used to deal with the complex decisions (Chenayah \& Takeda, 2005). The most well-known outranking methods are ELECTRE, ORESTE, and PROMETHEE (Bozbura et al., 2007).

The ELECTRE approach includes a number of methods that differ in the degree of complexity, the details of information required, and the nature of the underlying problem (Pavan \&Todeschini, 2009). In this study, ELECTRE III method has been applied for choosing the best weapon. This method is selected for two reasons: (a) A good decision-making model needs to tolerate vagueness or ambiguity because fuzziness and vagueness are common characteristics in many decision-making problems (Yu, 2002). ELECTRE III is capable of incorporating the fuzzy (imprecise and uncertain) nature of decision-making by using thresholds (Raju \& Duckstein, 2004; Takeda, 2001; Giannoulis \& Ishizaka, 2010; Gong \& Xu, 2006). (b) a large number of potential available alternative exist in the weapon selection and The ELECTRE III method is efficient when comparing large numbers of alternatives (Finlayson et al., 2004; Goicoechea, et al., 1982). This article consists of five main sections: section 2 briefly describes the proposed methods.; in section 3 the proposed model is presented; in section 4 the case study is discussed followed by conclusion in section 5 . 


\section{Methods}

\subsection{Simos method}

One of the most important parameters of ELECTRE III is the preference information of the decision maker expressed as weights for criteria (Tervonen et al., 2004). There are various weighting techniques proposed for ELECTRE methods (e.g. Simos, 1990; Mousseau, 1995; Hokkanen \& Salminen, 1997; Rogers \& Bruen, 1998). The Simos method is selected in this study for determining the weighting process. Simos proposed a very simple procedure, using a set of cards, allowing to determine indirectly numerical values for weights (Figueira \& Roy, 2002). This method can be easily understood by decision makers (Cavallaro, 2010) and has been applied to a wide range of decisionmaking problems (Shanian et al., 2008). The Simos method can be summarized as follows (Cavallaro, 2010):

(1) The name of each criterion is recorded on a card and these are given to the decision maker in random order.

(2) The person being questioned is then asked to put the cards in order of non-decreasing importance that he/she prefers and to insert blank cards for reflecting the gap between the ranked criteria while the criteria that are of the same importance are grouped in the same rank.

(3) Each criterion is assigned a position.

(4) The average weights are calculated for each rank by dividing the sum of the positions by the number of criteria.

(5) Finally, the relative weights (normalized weights) are calculated by dividing the average weights by the sum of all positions of the criteria. Table 1 illustrates the procedure of weight calculation using the above-mentioned approach.

Table 1

Simos Method for calculating criteria weights (Cavallaro, 2010).

\begin{tabular}{|c|c|c|c|c|c|c|}
\hline Ranking $\boldsymbol{r}^{\boldsymbol{a}}$ & Criteria & $\begin{array}{l}\text { No. of criteria in rank } \\
\text { r, } N_{r}\end{array}$ & Weight, W & $\begin{array}{l}\text { Average weights, } Q_{r}= \\
\sum W / N_{r}\end{array}$ & $\begin{array}{l}\text { Relative weights, } W_{r}= \\
\left(Q_{r} / \sum W\right) \mathbf{1 0 0}\end{array}$ & Total \\
\hline 1 & $\mathrm{~d}$ & 1 & 1 & 1 & 3.2 & $3.2 \times 1=3.2$ \\
\hline 2 & e & 1 & 2 & 2 & 6.4 & $6.4 \times 1=6.4$ \\
\hline 3 & $G, f$ & 2 & 3,4 & $(3+4) / 2=3.5$ & 11.2 & $11.2 \times 2=22.4$ \\
\hline 4 & - & - & (5) & - & - & - \\
\hline 5 & $\mathrm{~b}$ & 1 & 6 & 6 & 19.3 & $19.3 \times 1=19.3$ \\
\hline 6 & $\mathrm{a}, \mathrm{c}$ & 2 & 7,8 & $(7+8) / 2=7.5$ & 24.1 & $24.1 * 2=48.2$ \\
\hline Sum & 7 & & $31^{b}$ & & & $\approx 100$ \\
\hline
\end{tabular}

\subsection{ELECTRE III}

Benayoun et al. (1966) are believed to be the first who introduced the ELECTRE method as an outranking method for evaluating a MCDM problem (Shofade, 2011). The acronym ELECTRE stands for: Elimination Et Choix Traduisant la REalité (ELimination and Choice Expressing REality) (Ulubeyli \& Kazaz, 2009; Kaya \& Kahraman, 2011; Alemi et al., 2011). This method concentrates the analysis on the dominance relations among the alternatives (de Almeida, 2007). ELECTRE is a widely recognized evaluation method with a strong performance track record that can be employed to facilitate decision-making activities, which incorporate both qualitative and quantitative criteria (Huang \& Chen, 2005). Different versions of ELECTRE have been developed including ELECTRE I, IS, II, III, IV and TRI. All methods are based on the same fundamental concepts (Marzouk, 2011) and different ELECTRE methods may be different in how they define the outranking relations between alternatives and how they apply these relations to get the final ranking of the alternatives (Wang \& Triantaphyllou, 2008). ELECTRE I is designed for selection problems, ELECTRE TRI for assignment problems and ELECTRE II, III and IV for ranking problems (Marzouk, 2011; Roy, 1991; 
Shofade, 2011). References Roy (1991), Vincke (1992), Figueira et al. (2004) and Shofade (2011) provided more detailed ELECTRE methods.

Among ELECTRE methods, ELECTRE III is well known and has been widely used in practice. This method was designed to improve ELECTRE II, and thus to deal with inaccurate, imprecise, uncertain or ill-determination of data. This purpose was actually achieved, and ELECTRE III was applied with success during the last decades on a broad range of real-life applications (Figueira et al., 2005). The main difference between II and III is that they use various types of criteria. ELECTRE II uses the true criteria where no thresholds exist but The criteria used by ELECTRE III are pseudo criteria which involve the use of two-tiered thresholds (Wang \& Triantaphyllou, 2008). To use ELECTRE III, the following must be defined by decision makers for all criteria (Marzouk, 2011):

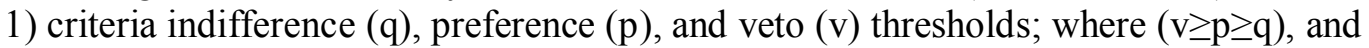

2) importance rating (wj) for each criterion $j$.

ELECTRE III method comprise two steps (Giannoulis \& Ishizaka, 2010):

Step 1: Construction of the outranking relation:

In this stage, choices are compared to each other in couples. This stage's output is Credibility matrix.

Step 2: Exploitation of the outranking relation: Two pre-rankings are then constructed with two antagonist procedures (ascending and descending distillation). The combination of the two preranking gives the final ranking.

The two distinct phases are depicted in Fig. 1. The complete description of the two steps is summarized in the following subsections.

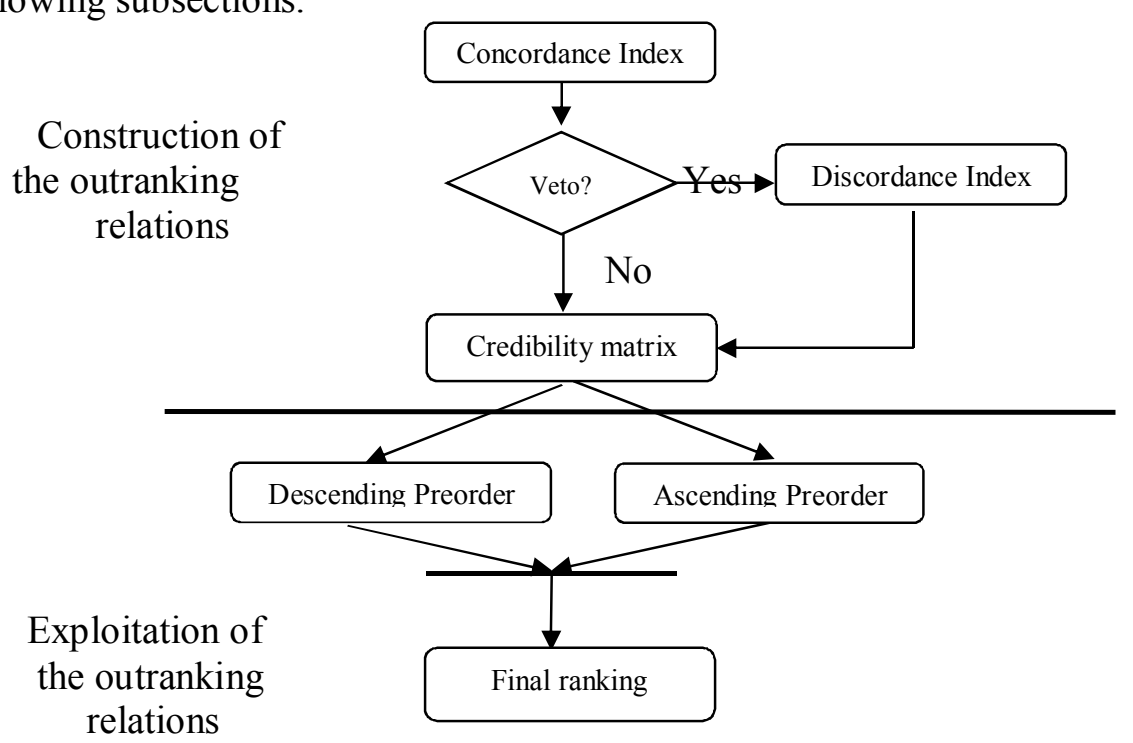

Fig. 1. ELECTRE III process flow (Giannoulis \& Ishizaka, 2010).

Step 1: Construction of the outranking relation (Montazer et al., 2009):

In this paper, we will use the following notation:

(i) $F=\left\{g_{1}, \ldots, g_{i}, \ldots, g_{n}\right\}$ is the set or family of criteria.

(ii) $J$ denotes the set of criteria indices.

(iii) $A=\left\{a_{1}, \ldots, a_{i}, \ldots, a_{n}\right\}$ is the set of alternatives.

(iv) $W=\left\{w_{1}, \ldots, w_{i}, \ldots, w_{n}\right\}$ is the weight vector modeling the preferences of the DM. Let us assume that $\sum_{j \in J} w_{j}=1$.

(v) $g_{j}\left(a_{i}\right)$ is the evaluation of criterion $g_{j}$ for alternative $a_{i}$. Let define the following comprehensive binary relational operators, to compare two alternatives, $a$ and $b$, as follows:

(vi) $P$ is the strong preference relation, i.e. $a P b$ denotes the relation " $a$ is strongly preferred over $b$ ". 
(vii) $I$ is the indifference relation, i.e. $a I b$ denotes the relation " $a$ is indifferent to $b$ ".

(viii) $Q$ is the weak preference relation, i.e. $a Q b$ denotes the relation " $a$ is weakly preferred over $b$ ", which means hesitation between indifference and preference.

(ix) $R$ is the incomparability relation, i.e. $a R b$ denotes that action $a$ and $b$ are incomparable.

(x) $S$ is the outranking relation, i.e. $a S b$ denotes that " $a$ is at least as good as $b$ ".

(xi) $>$ is the preference relation, i.e. $a>b$ denotes that $a$ is preferred (strongly or weakly) over $b$.

The thresholds of the ELECTRE III model are denoted as follows:

(xii) $q_{j}$ is the indifference threshold for the criterion $g_{j}$.

(xiii) $p_{j}$ is the preference threshold for the criterion $g_{j}$.

(xiv) $v_{j}$ is the veto threshold for the criterion $g_{j}$.

These thresholds can be constant and variable (directly or inversely) along the scale of each criterion. The construction of an outranking relation requires the definition of a credibility index for the outranking relation $a S b ; \rho(a, b)$ denotes such an index. It is defined using both a comprehensive concordance index, $c(a, b)$, and a discordance index for each criterion $g_{j} \in F$, that is, $d_{j}(a, b)$, for all $j \in J$. The concordance index is computed by considering individually for each criterion $g_{j}$ the support it provides for the assertion $a S_{j} b$.

Following the definition in ELECTRE III we calculate the partial concordance index :

$c_{j}(a, b)=\left\{\begin{array}{lr}1 & g_{j}(b)-g_{j}(a) \leq q_{j} \\ 0 & g_{j}(b)-g_{j}(a) \geq p_{j} \\ \frac{g_{j}(b)-g_{j}(a)-p_{j}}{q_{j}-p_{j}} & \text { otherwise }\end{array}\right.$

Thus $c_{j}(a, b)$ decreases linearly from 1 to 0 . After computing the partial concordance indices, the comprehensive concordance index is calculated as a weighted sum:

$c(a, b)=\sum_{j \in J} w_{j} \times c_{j}(a, b)$

This shapes the concordance matrix including all $c(a, b)$ for all pair-wise relations of alternatives. The discordance of a criterion $g_{j}$ describes the veto effect that the criterion provides against the assertion $a S_{j} b$. The discordance indices are computed separately for all criteria. A discordance index reaches its maximal value when criterion $g_{j}$ puts its veto tothe outranking relation; it is minimal when the criterion $g_{j}$ is not discordant with that relation. To define the value of the discordance index on the intermediate zone a linear interpolation isused. The partial discordance indices are computed as follows, for all $j \in J$ :

$$
d_{j}(a, b)=\left\{\begin{array}{lrr}
1 & \text { if } & g_{j}(b)-g_{j}(a)>v_{j} \\
0 & \text { if } & g_{j}(b)-g_{j}(a) \leq p_{j} \\
\frac{g_{j}(b)-g_{j}(a)-p_{j}}{v_{j}-p_{j}} & & \text { otherwise }
\end{array}\right.
$$


In ordinary ELECTRE III, the outranking relation is constructed by defining the credibility of the assertion $a S b$ as follows:

$\rho(a, b)=c(a, b) \prod_{j \epsilon V} \frac{1-d_{j}(a, b)}{1-c(a, b)} ; \quad V=\left\{j \epsilon J: d_{j}(a, b)>c(a, b)\right\}$

Step 2: Exploitation of the outranking relation (Marzouk, 2011):

Alternatives are ranked in two pre-orders, which are constructed in different ways. The first pre-order is obtained in a descending manner (Descending Distillation), selecting the best rated alternatives initially, and finishing with the worst. The second pre-order is obtained in an ascending manner (Ascending Distillation), selecting the worst rated alternatives initially, and finishing with the best. The two pre-orders which are set based on a qualification score for each alternative as follows:

Step 1: Set $\lambda_{0}$ equals to the maximum value of $S(a, b)$ in credibility matrix (A) as per Eq. (5).

$\lambda_{0}=\max _{a, b \in A} S(a, b)$

Step 2: A cut off level of outranking $\lambda_{1}$ is defined as the largest outranking score, which is just less than the maximum outranking score minus the discrimination threshold as per Eq. (6).

$\lambda_{0}=\max _{\left\{S(a, b)<\lambda_{0}-s\left(\lambda_{0}\right)\right\} \in A} S(a, b)$

where, $s\left(\lambda_{0}\right)$ is the discrimination threshold at the maximum level of outranking $\lambda_{0}$. At initial cut off level, a outranks b if $S(a, b)$ is greater than the cutoff level and $S(a, b)$ exceeds $S(b, a)$ by more than the discrimination threshold (see Eq. (7)) satisfying the condition, given in Eq. (8).

$s(\lambda)=0.3-0.15 \lambda$

$a S b$ if $S(a, b)>\lambda_{1}$ and $S(a, b)-S(b, a)>s(\lambda)$

Step 3: Every time $a$ outranks $b, a$ is given a score of +1 (strength) and $b$ is given -1 (weakness). For each alternative, the strengths and weaknesses are added together to give a final qualification score.

Step 4:Within Descending Distillation, the alternative with the highest qualification score is assigned to a rank and removed from the procedure, and the process is repeated for all remaining options.

Step 5: Within Ascending Distillation, the alternative with the lowest qualification score is assigned to a rank and removed from the procedure, and the process is repeated for all remaining options.

The results of the two procedures Descending Distillation and Ascending Distillation are combined to form complete ranking that is consistent with the two procedures.

\section{The proposed model}

The proposed model for the weapon selection problem, composed of simos and ELECTRE III methods, consists of three basic stages: (1) determine alternative weapons and the criteria evaluation,(2) Computing the weighting of evaluation criteria with simos method and Eq. (3) evaluation of alternatives with ELECTRE III and determination of the final rank. In the first stage, Alternative weapons and criteria for choices assessment were determined by expert team agreement. In the second step, weight of the criteria selected in the previous step was calculated using simos method. calculated weights of the criteria are approved by experts team and these weight values are used as ELECTRE III inputs. Weapon ranks are determined by using ELECTRE III method in the third stage. Finally, the best weapon was determined according to the ranking derived from ELECTRE III. Schematic diagram of the proposed model for weapon selection is provided in Fig.2. 


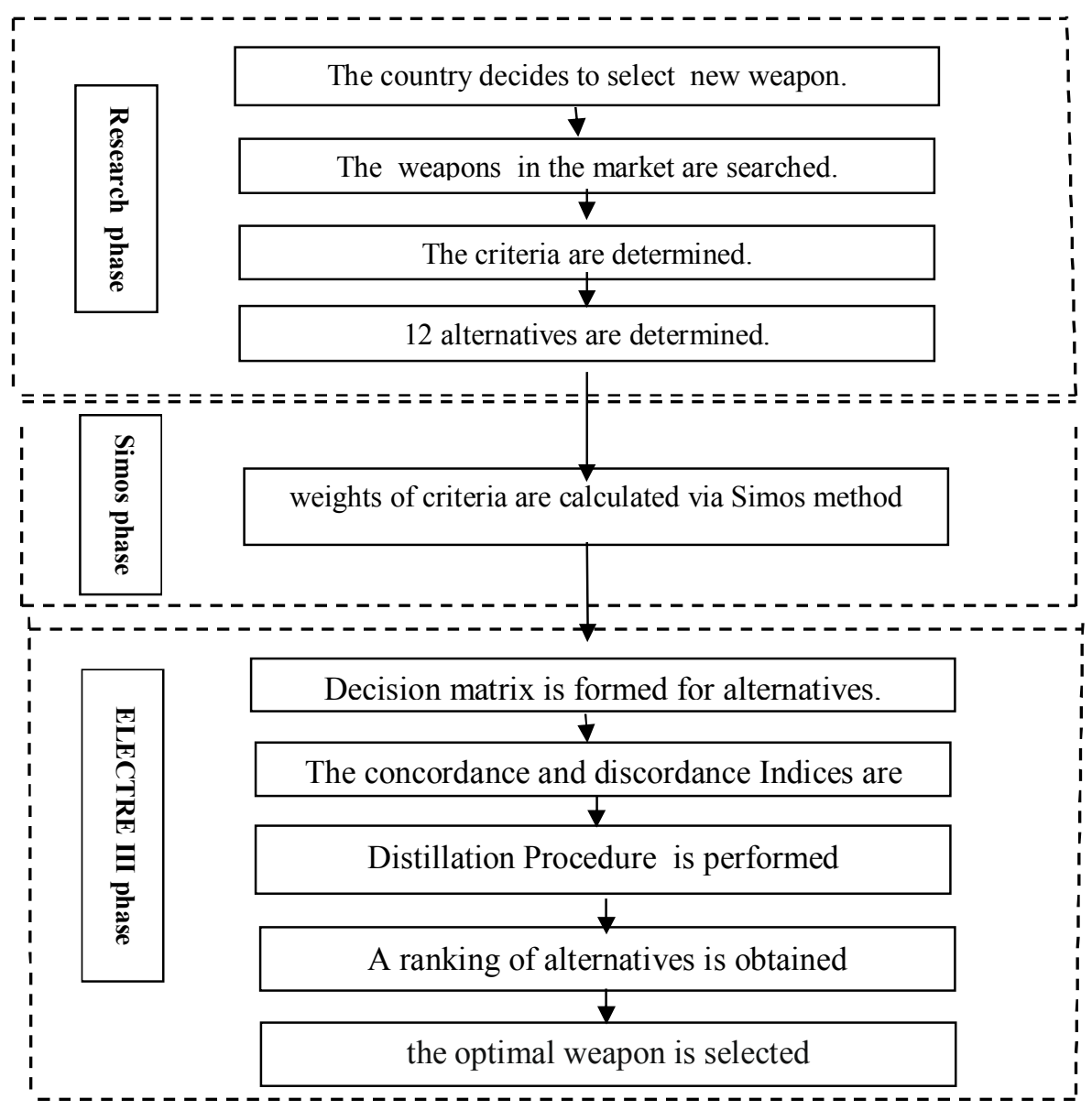

Fig. 2. Schematic diagram of the proposed model

\section{A numeric application of proposed model}

In this section, proposed model is examined for its efficiency by application to a real weapon selection problem. For this purpose, expert team was first established. 5 martial experts with a high level of knowledge, established professionals team. Professional team is gathered, the model proposed in the previous part, was applied step by step. At last, the preferred weapon was determined according to the results from the model. Details for suggested model's application stages are given will follow:

\subsection{Research phase}

This stage was performed in two stages:

\subsubsection{Determining the criteria}

For determining the criteria, widespread studies were first performed in subject's literature and criteria were extracted and presented to decision making team. After discussion and exchange of views among team members, and considering some team members opinions about similarity and overlap of some criteria, and also the fact that choices did not have any significant difference in some criteria, five criteria were chosen as final criteria for choices assessment and team members agreed on that. These criteria include: Weight $\left(C_{1}\right)$, Precision rate for striking the target $\left(C_{2}\right)$, Potential for constant shooting $\left(C_{3}\right)$, Potential of being applied in various climatic conditions $\left(C_{4}\right)$, Price $\left(C_{5}\right)$ 


\subsubsection{Alternatives determination}

In order to determine the criteria, professional team provided a list of the existing weapons, then they got to precise examination of properties and capabilities of the weapons available in the list and took apart any weapon which did not have the least necessary standards. Professional team's members acted severely in determining least standards necessary for weapons; At last, 12 weapons were determined for assessment based on the criteria.

\subsection{Simos phase}

The Simos method was used to calculate the weights (see paragraph-2-1). Having in mind, team members were separately asked to determine criteria's degree of importance for the implementation in this method. After acquisition of viewpoints, it was seen that there were some differences in criteria's arrangement according to team members' viewpoints. Finally, after discussions and exchange of views, decision making team members came to an agreement on a single arrangement. After determining criteria arrangement, steps of Simos method were applied and criteria weights were determined ( see Table 2).

Table 2

Simos Method for calculating criteria weights

\begin{tabular}{|c|c|c|c|c|c|c|c|}
\hline Ranking $\boldsymbol{r}^{a}$ & Criteria & $\begin{array}{l}\text { No. of criteria } \\
\text { in rank r, } N_{r}\end{array}$ & Weight, W & $\begin{array}{l}\text { Average } \\
\text { weights, } Q_{r}= \\
\sum W / N_{r}\end{array}$ & $\begin{array}{l}\text { Relative weights, } \\
\boldsymbol{W}_{r}=\left(\boldsymbol{Q}_{r} /\right. \\
\left.\sum \boldsymbol{W}\right) \mathbf{1 0 0}\end{array}$ & total & $\begin{array}{l}\text { Intermediate } \\
\text { Weight }\end{array}$ \\
\hline 1 & $C_{5}$ & 1 & 1 & 1 & 5.8824 & $5.8824 \times 1=5.8824$ & 6 \\
\hline 2 & $C_{4}$ & 1 & 2 & 2 & 11.7647 & $11.7647 \times 1=11.7647$ & 12 \\
\hline 3 & $C_{1}$ & 1 & 3 & 3 & 17.6471 & $17.6471 \times 1=17.6471$ & 18 \\
\hline 4 & & 1 & (4) & - & ---------- & --------- = & \\
\hline 5 & $C_{3}$ & 1 & 5 & 5 & 29.4118 & $29.4118 \times 1=29.4118$ & 29 \\
\hline 6 & $C_{2}$ & 1 & 6 & 6 & 35.2941 & $35.2941 \times 1=35.2941$ & 35 \\
\hline sum & & 5 & 17 & & & 100.0001 & 100 \\
\hline
\end{tabular}

Table 3

Weights and thresholds values

\begin{tabular}{rllll}
\hline Criteria & Weight & Indifference $(q)$ & Preference $(\mathrm{p})$ \\
\hline $\mathbf{C}_{\mathbf{1}}$ & 0.18 & 0.15 & 0.25 \\
$\mathbf{C}_{\mathbf{2}}$ & 0.35 & 0.5 & 1 \\
$\mathbf{C}_{\mathbf{3}}$ & 0.29 & 0.5 & 1 \\
$\mathbf{C}_{\mathbf{4}}$ & 0.12 & 0.5 & 1 \\
$\mathbf{C}_{\mathbf{5}}$ & 0.06 & 150 & 250 \\
\hline
\end{tabular}

\subsection{ELECTRE III phase}

Before implementation of ELECTRE III technique steps, information necessary for this method, including weight vector, criteria domain and decision matrix, must be determined. The vector of the criteria weight was defined by Simos method defined in previous step $(\mathrm{W}=0.18,0.35,0.29,0.12$, 0.06). Criteria domain were determined by team members and based on their experience and knowledge in the field of equipment and weapons. These domains are presented in Table 3. Decision matrix was determined using weapons properties and professional team viewpoints (Table 4). (The decision matrix entries state the alternatives performance in proportion to the criteria). In order to determine decision matrix rate, the criteria were divided into two groups according in terms of quantitative or qualitative criteria. In order to determine choices function compared with quantitative criteria $\left(C_{5}, C_{1}\right)$ available information in weapon properties were made. In addition, in order to determine choices function compared with qualitative criteria $\left(C_{2}, C_{3}, C_{4}\right)$, professional team's members were asked to perform their individual assessments using five measurements of very low (1), low (3), average (5), high (7), very high (9). Finally, team members agreed, arithmetic average was used for integrating team members individual assessments. 
Table 4

decision matrix

\begin{tabular}{|c|c|c|c|c|c|}
\hline & $\mathrm{C}_{1}[\mathrm{~kg}]$ & $\mathrm{C}_{2}[\mathrm{qs}]^{*}$ & $\mathrm{C}_{3}[\mathrm{qs}]^{*}$ & $\mathrm{C}_{4}[\mathrm{qs}]^{*}$ & $\mathrm{C}_{5}[\$]$ \\
\hline Direction of preference & Min & $\operatorname{Max}$ & Max & Max & Min \\
\hline$A_{1}$ & 3.2 & 7 & 5.4 & 7 & 1090 \\
\hline$A_{2}$ & 3.4 & 5.8 & 5.4 & 7 & 535 \\
\hline$A_{3}$ & 3.3 & 8 & 7 & 8.6 & 1100 \\
\hline $\boldsymbol{A}_{4}$ & 3.2 & 7.6 & 7.8 & 7 & 1300 \\
\hline$A_{5}$ & 3.3 & 8.6 & 3 & 6.6 & 930 \\
\hline$A_{6}$ & 3.4 & 7.6 & 7 & 7.8 & 1050 \\
\hline$A_{7}$ & 3.3 & 8.2 & 6 & 7 & 1550 \\
\hline$A_{8}$ & 3.6 & 7 & 5 & 9 & 725 \\
\hline$A_{9}$ & 3.2 & 7.6 & 6.6 & 6.6 & 1300 \\
\hline$A_{10}$ & 3.45 & 5 & 5 & 7 & 1030 \\
\hline$A_{11}$ & 3.4 & 6.6 & 6 & 8.6 & 980 \\
\hline$A_{12}$ & 3.3 & 5 & 5.8 & 8.6 & 820 \\
\hline
\end{tabular}

*Qualitative

After determination the necessary input data, The ELECTRE III model has been applied and the credibility matrix was obtained as per Table 5 . Then, the distillation procedure is applied to obtain the Descending and Ascending pre-orders as per Fig. 3. Finally The results of the two procedures Descending Distillation and Ascending Distillation are combined to form complete ranking that is consistent with the two procedures (see Fig. 3). According to the results from choices rating through ELECTRE III method, A3 case is the optimum weapon.

Table 5

Credibility matrix

\begin{tabular}{|c|c|c|c|c|c|c|c|c|c|c|c|c|}
\hline & $A_{1}$ & $A_{2}$ & $A_{3}$ & $\boldsymbol{A}_{4}$ & $A_{5}$ & $A_{6}$ & $A_{7}$ & $A_{8}$ & $A_{9}$ & $A_{10}$ & $A_{11}$ & $A_{12}$ \\
\hline$\overline{A_{1}}$ & 1 & 0.94 & 0.24 & 0.64 & 0.644 & 0.568 & 0.592 & 0.82 & 0.64 & 1 & 0.822 & 0.82 \\
\hline$A_{2}$ & 0.56 & 1 & 0.24 & 0.27 & 0.65 & 0.288 & 0.592 & 0.53 & 0.27 & 1 & 0.612 & 0.88 \\
\hline$A_{3}$ & 1 & 0.94 & 1 & 0.826 & 0.918 & 1 & 1 & 0.94 & 1 & 1 & 1 & 0.94 \\
\hline$A_{4}$ & 0.964 & 0.94 & 0.85 & 1 & 0.59 & 0.868 & 0.93 & 0.82 & 1 & 0.94 & 0.82 & 0.82 \\
\hline$A_{5}$ & 0.71 & 0.65 & 0.59 & 0.71 & 1 & 0.59 & 0.71 & 0.557 & 0.71 & 0.71 & 0.59 & 0.59 \\
\hline$A_{6}$ & 0.91 & 0.94 & 0.928 & 0.736 & 0.65 & 1 & 0.93 & 0.82 & 0.91 & 1 & 0.928 & 0.88 \\
\hline$A_{7}$ & 0.94 & 0.94 & 0.53 & 0.65 & 0.94 & 0.578 & 1 & 0.82 & 0.882 & 0.94 & 0.82 & 0.82 \\
\hline$A_{8}$ & 0.82 & 0.886 & 0.18 & 0.46 & 0.47 & 0.55 & 0.18 & 1 & 0.46 & 1 & 0.62 & 0.646 \\
\hline$A_{9}$ & 0.964 & 0.94 & 0.85 & 0.71 & 0.59 & 0.82 & 0.93 & 0.82 & 1 & 0.94 & 0.82 & 0.82 \\
\hline$A_{10}$ & 0.47 & 0.73 & 0.24 & 0.18 & 0.65 & 0.288 & 0.36 & 0.47 & 0.18 & 1 & 0.24 & 0.67 \\
\hline$A_{11}$ & 0.91 & 0.94 & 0.36 & 0.27 & 0.65 & 0.36 & 0.65 & 0.94 & 0.502 & 1 & 1 & 0.994 \\
\hline$A_{12}$ & 0.65 & 0.73 & 0.36 & 0.36 & 0.65 & 0.36 & 0.65 & 0.65 & 0.476 & 1 & 0.65 & 1 \\
\hline
\end{tabular}

\section{Sensitivity analysis}

Sensibility analysis for the purpose of certainty of the yielded results is one of the steps that decision makers should pay a special attention to, particularly when there are some uncertainty and vagueness about the input data. In the present study, stability rate in choices rating was examined through modification in $\mathrm{p} \& \mathrm{q}$ parameters to $\pm 10 \%$, and $\pm 20 \%$ (see Table 6 ). Results showed that rating has the acquired stability, so that despite existence of modification in parameters $\mathrm{p}$ and $\mathrm{q}, A_{3}$ choice was determined as the best choice in all cases. Results for sensibility analysis are represented in Table 7.

Table 6

Sensitivity analysis: $10 \%$ and $20 \%$ change in thresholds $\mathrm{p}$ and $\mathrm{q}$.

\begin{tabular}{crrrrrrrr}
\hline \multirow{2}{*}{ Criteria } & \multicolumn{2}{c}{$(\mathrm{q})$} & \multicolumn{2}{c}{$(\mathrm{p})$} & \multicolumn{2}{c}{$(\mathrm{q})$} & \multicolumn{2}{c}{$(\mathrm{p})$} \\
& \multicolumn{1}{c}{$-10 \%$} & $+10 \%$ & $-10 \%$ & $+10 \%$ & $-20 \%$ & $+20 \%$ & $-20 \%$ & $+20 \%$ \\
\hline $\mathrm{C}_{1}$ & 0.135 & 0.165 & 0.225 & 0.275 & 0.120 & 0.180 & 0.2 & 0.3 \\
$\mathrm{C}_{2}$ & 0.45 & 0.55 & 0.9 & 1.1 & 0.4 & 0.6 & 0.8 & 1.2 \\
$\mathrm{C}_{3}$ & 0.45 & 0.55 & 0.9 & 1.1 & 0.4 & 0.6 & 0.8 & 1.2 \\
$\mathrm{C}_{4}$ & 0.45 & 0.55 & 0.9 & 1.1 & 0.4 & 0.6 & 0.8 & 1.2 \\
$\mathrm{C}_{5}$ & 135 & 165 & 225 & 275 & 120 & 180 & 200 & 300 \\
\hline
\end{tabular}




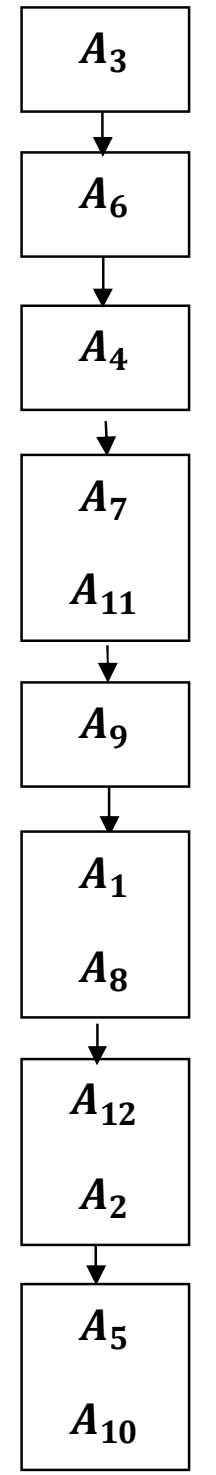

(a)

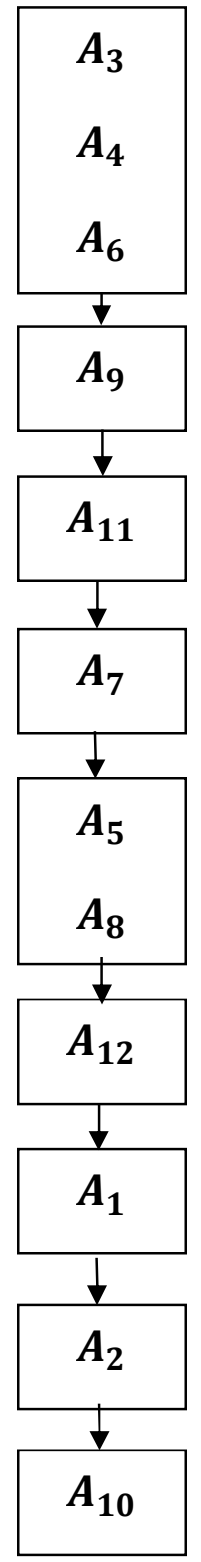

(b)

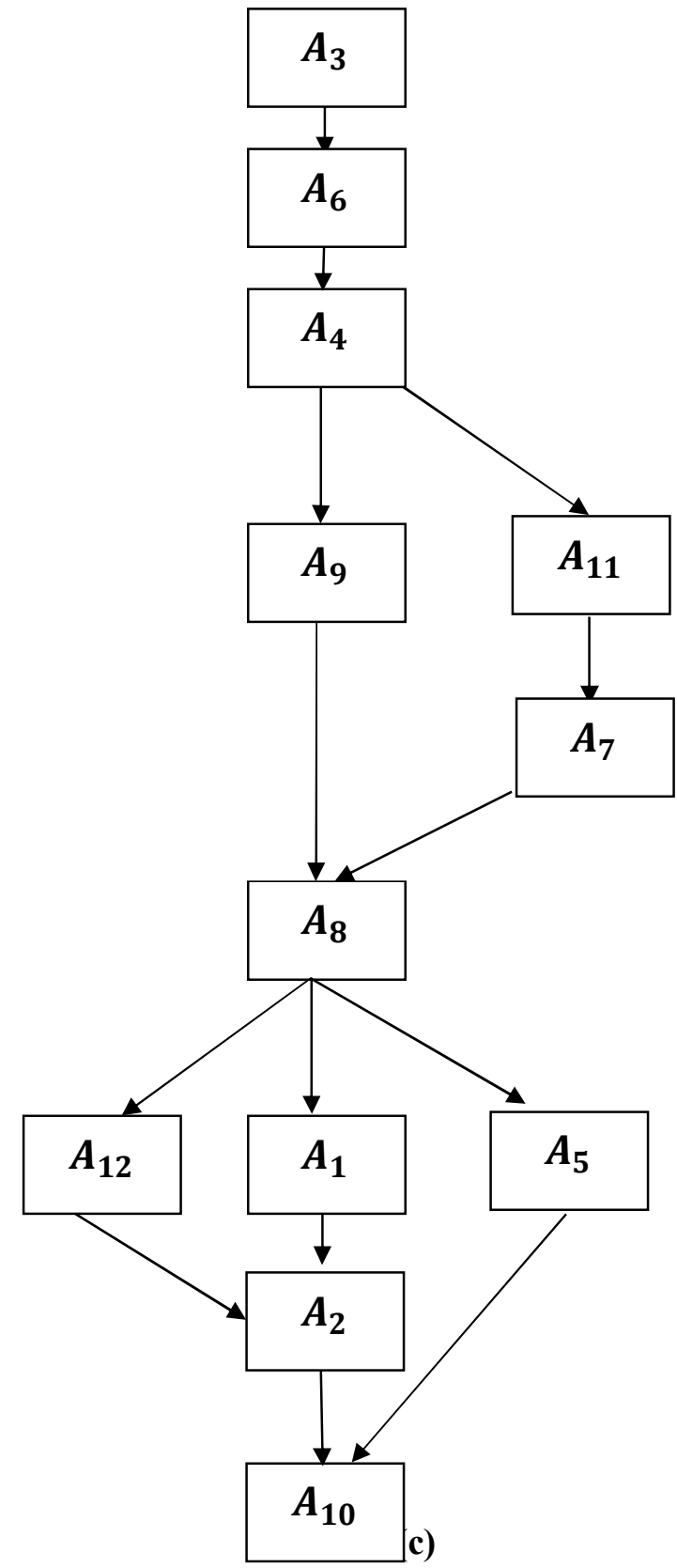

c)

Fig. 3. (a) Descending Distillation, (b) Ascending Distillation, (c) Final Ranking

Table 7

Sensitivity analysis: results of $10 \%$ change in thresholds $\mathrm{p}$ and $\mathrm{q}$.

\begin{tabular}{|c|c|c|c|c|c|c|c|c|}
\hline \multirow[t]{2}{*}{ Ranking } & \multicolumn{8}{|c|}{ Results } \\
\hline & (q) $-10 \%$ & $(q)+10 \%$ & (p) $-10 \%$ & (p) $+10 \%$ & (q) $-20 \%$ & (q) $+20 \%$ & (p) $-20 \%$ & (p) $+\% 20$ \\
\hline 1 & $A_{3}$ & & $A_{3}$ & & $A_{3}$ & & $A_{3}$ & \\
\hline 2 & $A_{6}$ & & $A_{4}$ & & $A_{4}$ & & $A_{4}$ & \\
\hline 3 & $A_{4}$ & & $A_{6}$ & & $A_{6}$ & & $A_{6}$ & \\
\hline 4 & $A_{11}$ & & $A_{11}$ & & $A_{11}$ & Stable & $A_{11}$ & Stable \\
\hline 5 & $A_{7}$ & Stable ranking & $A_{7}$ & Stable & $A_{7}$ & Ranking & $A_{7}$ & Ranking \\
\hline 6 & $A_{9}$ & & $A_{9}$ & ranking & $A_{9}$ & & $A_{9}$ & \\
\hline 7 & $A_{8}$ & & $A_{1}, A_{8}$ & & $A_{8}$ & & $A_{1}, A_{8}$ & \\
\hline 8 & $A_{1}, A_{5}, A_{12}$ & & $A_{2}, A_{5}, A_{12}$ & & $A_{1}, A_{5}, A_{12}$ & & $A_{2}, A_{5}, A_{12}$ & \\
\hline 9 & $A_{2}$ & & $A_{10}$ & & $A_{2}$ & & $A_{10}$ & \\
\hline 10 & $A_{10}$ & & & & $A_{10}$ & & & \\
\hline
\end{tabular}




\section{Conclusion}

In this paper, an integrative and systematic decision making model was represented based on ELECTRE III method for an infantry rifle selection. In the suggested model, first, acceptable choices and the criteria based on which these choices assessed were determined by professionals team. Then, having determined the criteria through Simos method, ELECTRE method compared choices in couples and determined the optimum choice. Results for the application of the model in a real case of choosing an infantry rifle, showed its effectiveness in practice. In addition, a sensibility analysis was performed in order to evaluate stability rate in final rating from the model, and the results showed that modification in input parameters did not change the optimum choice. Application of other multicriteria methods or integrating these methods with one another, for the purpose of weapon selection and comparing the results derived from them, are among the existing fields for future research.

\section{References}

Alemi, M., Jalalifar, H., Kamali, G. R., \& Kalbasi, M. (2011). A mathematical estimation for artificial lift systems selection based on ELECTRE model. Journal of Petroleum Science and Engineering, 78(1), 193-200.

Bozbura, F. T., Beskese, A., \& Kahraman, C. (2007). Prioritization of human capital measurement indicators using fuzzy AHP. Expert Systems with Applications, 32(4), 1100-1112.

Cavallaro, F. (2010). A comparative assessment of thin-film photovoltaic production processes using the ELECTRE III method. Energy Policy, 38(1), 463-474.

Chen, S. M. (1996). Evaluating weapon systems using fuzzy arithmetic operations. Fuzzy sets and systems, 77(3), 265-276.

Chenayah, S., \& Takeda, E. (2005). Eigenvector Procedure based on Weighted Preference Flows in Multicriteria Outranking Analysis. OSIPP Discussion Papers in Economics and Business, 05-22.

Cheng, C. H., \& Mon, D. L. (1994). Evaluating weapon system by analytical hierarchy process based on fuzzy scales. Fuzzy sets and systems, 63(1), 1-10.

Cheng, C. H. (1997). Evaluating naval tactical missile systems by fuzzy AHP based on the grade value of membership function. European Journal of Operational Research, 96(2), 343-350.

Cheng, C. H., Yang, K. L., \& Hwang, C. L. (1999). Evaluating attack helicopters by AHP based on linguistic variable weight. European Journal of Operational Research, 116(2), 423-435.

Cheng, C. H. (1999). Evaluating weapon systems using ranking fuzzy numbers. Fuzzy Sets and Systems, 107(1), 25-35.

Cheng, C. H., \& Lin, Y. (2002). Evaluating the best main battle tank using fuzzy decision theory with linguistic criteria evaluation. European Journal of Operational Research, 142(1), 174-186.

Cheng, C. H., \& Lin, Y. (2002). Evaluating the best main battle tank using fuzzy decision theory with linguistic criteria evaluation. European Journal of Operational Research, 142(1), 174-186.

Figueira, J., \& Roy, B. (2002). Determining the weights of criteria in the ELECTRE type methods with a revised Simos' procedure. European Journal of Operational Research, 139(2), 317-326.

Figueira, J., Greco, S., \& Ehrgott, M. (2004). Multiple Criteria Decision Analysis: State of the Art Surveys. Springer, New York.

Figueira, J., Mousseau, V., \& Roy, B. (2005). ELECTRE methods. In J. Figueira, S. Greco,\& M. Ehrgott (Eds.), Multiple criteria decision analysis, state of the art surveys(pp. 133-162). Springer.

Finlayson, J., Knowles, I. M., \& Fraser, T., J. (2004). Forage Master: A decision tool for selecting and managing forages for New Zealand sheep and beef farms. Proceedings of the New Zealand Grassland Association, 66, 207-213.

Giannoulis, C., \& Ishizaka, A. (2010). A Web-based Decision Support System with ELECTRE III for a Personalised Ranking of British Universities. Decision Support Systems, 48(3), 488-497.

Goicoechea, A., Hansen, D., Duckstein, L. (1982). Introduction to multi objective analysis with engineering and business application. Wiley, New York.

Gong, J., \& Xu, J. (2006). The integration of valued outranking relations in ELECTRE methods for ranking problem. World Journal of Modelling and Simulation, 2(1), 3-14. 
Hokkanen, J., \& Salminen, P. (1997). ELECTRE III and IV decision aids in an environmental problem. Journal of Multi-Criteria Decision Analysis, 6(4), 215-226.

Huang, W-C., Chen, C-H. (2005). Using the ELECTRE II method to apply and analyze the differentiation theory. Proceedings of the Eastern Asia Society for Transportation Studies, 5, 2237-2249.

Hwang, C. L., \& Yoon, K. (1981). Multiple attribute decision making-Methods and applications. Heidelberg: Springer-Verlag.

Kaya, T., \& Kahraman, C. (2011). An integrated fuzzy AHP-ELECTRE methodology for environmental impact assessment. Expert Systems with Applications, 38(7), 8553-8562.

Lee, J., Kang, S. H., Rosenberger, J., \& Kim, S. B. (2010). A hybrid approach of goal programming for weapon systems selection. Computers \& Industrial Engineering, 58(3), 521-527.

Marzouk, M. M. (2011). ELECTRE III model for value engineering applications. Automation in Construction, 20(5), 596-600.

Mon, D. L., Cheng, C. H., \& Lin, J. C. (1994). Evaluating weapon system using fuzzy analytic hierarchy process based on entropy weight. Fuzzy sets and systems, 62(2), 127-134.

Montazer, G. A., Saremi, H. Q., \& Ramezani, M. (2009). Design a new mixed expert decision aiding system using fuzzy ELECTRE III method for vendor selection. Expert Systems with Applications, 36(8), 10837-10847.

Mousseau, V. (1995). Eliciting information concerning the relative importance of criteria. In: Pardalos, Y., Siskos, C., Zopounidis, C. (Eds.), Advances in Multicriteria analysis. Kluwer Academic Publishers.

Papadopoulos, A., \& Karagiannidis, A. (2008). Application of the multi-criteria analysis method Electre III for the optimisation of decentralised energy systems. Omega, 36(5), 766-776.

Pavan, M., \& Todeschini, R. (2009).Multicriteria Decision-Making Methods.591-629.

Pohekar, S. D., \& Ramachandran, M. (2004). Application of multi-criteria decision making to sustainable energy planning - a review. Renewable and Sustainable Energy Reviews, 8(4), 365-381.

Raju, K., \& Duckstein, L. (2004). Integrated application of cluster and multicriterion analysis for ranking water resources planning strategies: a case study in Spain. Journal of Hydroinformatics, 6, 295-307.

RogerS, M., \& Bruen, M. (1998). A new system for weighting environmental criteria for use within ELECTRE III. European Journal of Operational Research,107(3), 552-563.

Roy, B. (1968). Classement et choix en présence de points de vue multiples. RAIRO-Operations Research-Recherche Opérationnelle, 2(6), 57-75.

Roy, B. (1991). The outranking approach and the foundations of ELECTRE methods. Theory and decision, 31(1), 49-73.

Shanian, A., Milani, A. S., Carson, C., \& Abeyaratne, R. C. (2008). A new application of ELECTRE III and revised Simos' procedure for group material selection under weighting uncertainty. Knowledge-Based Systems, 21(7), 709-720.

Shofade, O. J. S. (2011). Considering hierarchical structure of criteria in ELECTRE decision aiding methods. Master thesis, University of Rovira and Virgili.

Simos, J. (1990). Evaluerl'impactsurl'environnement: Une approach eoriginal eparl'analyse multicritere et la negociation. Presses Polytechniques et Universitaires Romandes, Lausanne.

Takeda, E. (2001). A method for multiple pseudo-criteria decision problems. Computers \& Operations Research, 28, 1427-1439.

Tervonen, T., Figueira, J., Lahdelma, R., \& Salminen, P. (2004). An inverse approach for ELECTRE III (p. 17). Coimbra, Portugal: Instituto de Engenharia de Sistemas e Computadores de Coimbra INESC.

Teixeira de Almeida, A. (2007). Multicriteria decision model for outsourcing contracts selection based on utility function and ELECTRE method. Computers \& Operations Research, 34(12), 3569-3574.

Ulubeyli, S., \& Kazaz, A. (2009). A multiple criteria decision-making approach to the selection of concrete pumps. Journal of Civil Engineering and Management, 15(4), 369-376.

Vincke, P. (1992). Multicriteria Decision Aid. Wiley, NewYork.

Wang, X., Triantaphyllou, E. (2008). Ranking irregularities when evaluating alternatives by using some ELECTRE methods. Omega, 36, 45-63.

Yu, C. S. (2002). A GP-AHP method for solving group decision-making fuzzy AHP problems. Computers and Operations Research, 29, 1969-2001. 